\title{
Obstetric Hemorrhage, its role in maternal morbidity and mortality and the importance of its diagnosis, prevention and timely management
}

\author{
Hemorragia obstétrtica, su papel en la morbimortalidad materna e importancia de su diagnóstico, \\ prevención y manejo oportuno \\ Ixchel S. Reyes Espinoza ${ }^{a}$
}

\begin{abstract}
:
Background: In recent years, different international and national campaigns have been implemented to combat obstetric haemorrhage. Maternal mortality (MM) is one of the main concerns of public health and represents a good indicator to measure the quality of care, an indicator that also allows to establish the socioeconomic differences between countries. There are still many activities to be carried out and achieve the objective set by the World Health Organization (WHO) and the Latin American Federation of Societies in Obstetrics and Gynaecology (FLASOG) "Zero deaths due to haemorrhage". Objective: Based on the scientific evidence available, deepen the knowledge of the role of obstetric haemorrhage as the main avoidable cause of maternal morbidity and mortality. Methodology: retrospective study through the search of original articles and systematic reviews in: Elsevier, Lancet, Intramed, PubMed, EMBASE, ScienceDirect and Cochrane Library. The following keywords were used for all sites: "Obstetric haemorrhage", "Maternal mortality and obstetric haemorrhage", "Maternal morbidity and obstetric haemorrhage", "Postpartum, late, secondary haemorrhage". The items with the highest level of evidence were selected. Conclusions: Obstetric haemorrhage is still a potential cause of maternal and fetal morbidity and mortality. Its appearance at any time of pregnancy is a cause for concern and alarm. Despite advances in obstetric and anesthetic care, its treatment remains a challenge for the surgical team, anesthesiologist, gynaecologist and Pediatrician.
\end{abstract}

Keywords:

Obstetric Haemorrhage, Maternal Mortality and Obstetric Hemorrhage, Maternal Morbidity and Obstetric Hemorrhage, Postpartum, Late, Secondary Hemorrhage

Resumen:

Introducción: En los últimos años, diferentes campañas internacionales y nacionales se han implementado para combatir la hemorragia obstétrica. La mortalidad materna (MM) es una de las principales preocupaciones de la salud pública y representa un buen indicador para medir la calidad asistencial, indicador que permite, además, establecer las diferencias socioeconómicas entre los países. Aún hay muchas actividades por realizar y lograr el objetivo planteado por la Organización Mundial de la Salud (OMS) y por la Federación Latinoamericana de Sociedades en Obstetricia y Ginecología (FLASOG) "Cero muertes por Hemorragia". Objetivo: Con base en la evidencia científica disponible profundizar en el conocimiento del papel que desempeña la hemorragia obstétrica como principal causa evitable de morbimortalidad materna. Metodología: estudio retrospectivo mediante la búsqueda de artículos originales y revisiones sistemáticas en: Elsevier, Lancet, Intramed, PubMed, EMBASE, ScienceDirect y Biblioteca Cochrane. Para todos los sitios se utilizaron las palabras clave: "Hemorragia obstétrica", "Mortalidad Materna y hemorragia obstétrica", "Morbilidad Materna y hemorragia obstétrica", "Hemorragia posparto, tardía, secundaria". Se seleccionaron los artículos de mayor nivel de evidencia. Conclusiones: La hemorragia obstétrica es todavía una causa potencial de morbimortalidad materna y fetal. Su aparición en cualquier momento del embarazo es motivo de preocupación y alarma. A pesar de los avances en la atención obstétrica y anestésica su tratamiento sigue siendo todo un reto para el equipo quirúrgico, anestesiólogo, ginecoobstetras y Pediatra.

Palabras Clave:

Hemorragia obstétrica, Mortalidad Materna y hemorragia obstétrica, Morbilidad Materna y hemorragia obstétrica, Hemorragia posparto, tardía, secundaria 


\section{INTRODUCTION}

Maternal Death is a public health phenomenon that is linked to the social, cultural, technological and even economic development of a nation, a region or simply a social conglomerate; For this reason, for decades the maternal mortality ratio has been used as an extremely sensitive indicator of social development, as a way of approaching inequality and social injustice in countries like Mexico, even with the facilities provided by the modernity. ${ }^{1}$

Integrating the study of morbidity into the study of mortality increases the opportunity to identify the factors that contribute to this event from pregnancy without complications to death and allows corrective measures to be taken in a timelier manner. During pregnancy, hemorrhages of the third trimester or postpartum and the hypertensive disease of pregnancy represent the most frequent risk factors and which in turn also become the first two causes of maternal mortality in the world. ${ }^{2}$

The sequelae or complications that may occur during pregnancy are as important as the mortality itself, since they are very frequent and affect the quality of life of the woman who survives these problems. ${ }^{3}$

Each year, nearly eight million women suffer complications related to pregnancy and 287,000 die from these causes around the world. The recognition of the burden generated by the complications of pregnancy has given rise to the concept of extreme or severe maternal morbidity, which is defined as the event that causes a serious complication during pregnancy, childbirth or puerperium putting at risk the life of the woman and requires immediate attention in order to avoid death. In Mexico it has been pointed out that approximately $15 \%$ of pregnancies present obstetric complications. ${ }^{4}$

Within the causes of Maternal Morbidity and Mortality we find Obstetric Hemorrhage leading the list, which represents the main death cause in developing countries like ours. The multidisciplinary management of obstetric hemorrhage has contributed to the decrease in mortality, however, the overall rate of secondary deaths to Obstetric Hemorrhage in low income countries has been increasing. The World Health Organization (WHO) reports that $50 \%$ of maternal deaths are secondary to Obstetric Hemorrhage and its complications, which occurs in $10.5 \%$ of all births. ${ }^{5}$

The early recognition of Obstetric Hemorrhage is considered a diagnostic challenge, since the blood loss remains hidden and difficult to quantify, as a result of the dilution of amniotic fluid and the physiological changes of pregnancy that mask the clinical signs of hypovolemia. For the diagnostic approach, there are currently Clinical Practice Guidelines that aim at making available for healthcare staff, recommendations based on the best available evidence. Although the knowledge of the Obstetric Hemorrhage is increasing, the investigations have been realized fundamentally in patients with massive hemorrhage associated with trauma. Few are the studies focused on the postpartum hemorrhage. ${ }^{6}$

\section{BACKGROUND}

Maternal health has been a priority in health policies in the last decade, which has been reflected in a decrease in morbidity and mortality in the world.

The World Health Organization (WHO) systematic review proposal on maternal morbidity and mortality for the year 19992000 was aimed at making a world map of alterations in reproductive health, knowing the incidence / prevalence of morbidity and rates of fatal cases related to maternal morbidity, finding that data on women's health are scarce and in some countries non-existent or of poor quality, which hinders the comparison between them, in addition to the difficulty to analyze them given that the methodology used in their collection and procedures is unknown. ${ }^{7}$

Regarding morbidity, Ashford et al. Report that, of 120,000,000 births per year in the world, $50 \%$ presented some complication and approximately $13 \%$ to $17 \%$ presented some disability as a consequence. They point out that, for each maternal death, 30 women had presented serious conditions, estimating that $11 \%$ developed hemorrhages. ${ }^{6,7}$

In 2016 Camacho and Rubio mentioned that it is important that health personnel who care for pregnant women remain alert to the onset of postpartum hemorrhage, since timely management depends on avoiding complications such as mortality or extreme maternal morbidity. ${ }^{8}$

\section{METHODOLOGY}

Retrospective study by searching original articles and systematic reviews in the databases: Intramed, Lancet, Elsevier, PubMed, EMBASE, ScienceDirect and Cochrane Library from 2006 to 2018. The following keywords were included in the different search engines: "Obstetric hemorrhage", "Maternal mortality and obstetric hemorrhage", "Maternal morbidity and obstetric hemorrhage", "Postpartum, late, secondary hemorrhage".

After the bibliographic search, the most relevant articles related to evidence-based clinic. Information on 29 documents was collected. Of these, four corresponded to international clinical practice guidelines for the diagnosis and management of obstetric hemorrhage. The remaining articles studied were compilations and updates of each one of the clinical situations that can be the beginning of obstetric hemorrhage.

\section{EPIDEMIOLOGY}

According to the $\mathrm{WHO}$, around 830 women worldwide die every day from causes related to pregnancy complications or childbirth. In 2015, estimates were made of 303,000 deaths of women during pregnancy, childbirth or the puerperium. Deaths 
generally occur in developing countries and most of these deaths could have been prevented. ${ }^{9}$

Most of the complications that occur during pregnancy, childbirth or puerperium are preventable or treatable. Such is the case of obstetric hemorrhage that occurs frequently after delivery. Severe hemorrhage can kill a woman's life within two hours if she does not receive adequate care. ${ }^{10}$

The main reasons for this high incidence are: the lack of assisted delivery access by trained personnel and the inadequate or limited practice of active management of the delivery. According to Cowen, when the patient is assisted in the health services, the delay in the recognition of hypovolemia and the inadequate volume replacement are the main reason for Maternal Death. ${ }^{11}$ It is estimated that around 14 million women suffer severe blood loss after childbirth, $1 \%$ of them die and an additional $12 \%$ survive with severe anemia. ${ }^{12}$

According to data from the General Direction of Epidemiology, the ratio of Maternal Mortality (RMM) calculated for week 49 of 2018 was 29.8 deaths per 100 thousand estimated births, representing a decrease of 13.1 percentage points compared to that registered on the same date of the year 2017. The obstetric hemorrhage continued to represent the highest percentage of the causes of these deaths, with 149 cases corresponding to $24 \%$ of the deaths. ${ }^{13}$

\section{DEFINITION}

Hemorrhage is physiological after delivery. However, when it exceeds a certain amount, it is considered pathological. It is difficult to define obstetric hemorrhage because there is no universal definition established with precision, which is why there are many concepts (see Table 1) from the parameters that can lead to hemodynamic changes dependent on comorbidities or the current status of women. ${ }^{14-17}$

Table 1 Summary of the main definitions of obstetric hemorrhage

\section{CLINICAL GUIDES}

\begin{tabular}{|c|c|}
\hline Australians $2008^{15}$ & $\begin{array}{l}\text { Blood loss }>500 \mathrm{~mL} \text { after } \\
\text { delivery and } 750 \mathrm{~mL} \text { after } \\
\text { cesarean section. }\end{array}$ \\
\hline Austrian, $2008^{14}$ & $\begin{array}{l}\text { Blood loss of } 500-1,000 \mathrm{~mL} \\
\text { and signs of hypovolemic } \\
\text { shock or bleeding }>1,000 \mathrm{~mL}\end{array}$ \\
\hline German, $2008^{14}$ & $\begin{array}{l}\text { Blood loss }>500 \mathrm{~mL} \text { after } \\
\text { delivery. }\end{array}$ \\
\hline $\begin{array}{l}\text { World Health Organization } \\
(\mathrm{WHO})^{16}\end{array}$ & $\begin{array}{l}\text { Primary: estimated loss> } \\
500-1,000 \mathrm{~mL} \text { or signs of } \\
\text { shock. }\end{array}$ \\
\hline $\begin{array}{l}\text { RCOG* United Kingdom } \\
2009^{17}\end{array}$ & $\begin{array}{l}\text { Serious: loss }>1,000 \mathrm{~mL} \text { in } \\
24 \mathrm{hrs}\end{array}$ \\
\hline
\end{tabular}

*RCOG: Royal College of Obstetricians and Gynecologists.
The quantification of hemorrhage is particularly difficult during labor and / or cesarean section because the blood is mixed with other fluids. In addition, when a postpartum atony occurs there may be a large amount of blood retained in the uterus, whether the delivery was by caesarean section, or if it was a eutocic delivery. ${ }^{18,19}$

\section{DIAGNOSTIC CRITERIA}

According to the Mexican Clinical Practice Guidelines, the diagnostic criteria to obstetric hemorrhage are:

- Lost more than $25 \%$ of the volume. (50\% of the volume in 3 hours).

-Decrease in hematocrit 10 or more points.

-Approximate loss of $150 \mathrm{~mL} /$ minute in 20 minutes.

-Download of hemoglobin $4 \mathrm{~g} / \mathrm{dL}$

-Hemodynamic changes: that triggers the presence of symptoms: weakness, vertigo, syncope and / or signs: hypotension, tachycardia or oliguria. These data are present when the patient has lost a significant amount of blood. ${ }^{18-20}$

\section{CLASIFICATION}

\section{Severe Persistent Obstetric Hemorrhage}

Presence of active bleeding greater than $1000 \mathrm{~mL}$ within the first 24 hours after delivery, which continues despite initial treatment with uterotonics. ${ }^{21,22}$

\section{Primary postpartum hemorrhage}

Bleeding that occurs within the first 24 hours after birth related in $80 \%$ of cases with uterine atony. In turn, this classification is subdivided by the amount of bleeding in: $\operatorname{minor}(500-100 \mathrm{~mL})$ or greater (more than $1000 \mathrm{~mL}$ ); major hemorrhage can also be subdivided into moderate $(1001 \mathrm{~mL}-2000 \mathrm{~mL})$ and severe (more than $2000 \mathrm{~mL}$ ). For cases in which a woman with a low body mass index (less than 18.5) is involved, a lower blood loss may be clinically significant. ${ }^{20-22}$

\section{Secondary postpartum hemorrhage}

Defined as abnormal or excessive bleeding from the birth canal between 24 hours and 12 weeks postnatally. ${ }^{22}$

\section{Severe Obstetric Hemorrhage}

Blood loss of obstetric origin, with the presence of any of the following criteria: loss of $25 \%$ of blood volume, drop in hematocrit greater than 10 points, presence of hemodynamic changes or loss greater than $150 \mathrm{~mL} / \mathrm{min}^{22}$

\section{Obstetric Hemorrhage in Progress}

Also called uncontrollable or active obstetric hemorrhage, defined as the loss of more than $2000 \mathrm{~mL}$ of blood. ${ }^{23}$

\section{CAUSES}




\section{Premature Detachment ofcental Abruption}

Sometimes it is not visible because it accumulates as a retroplacental hematoma (even 1 to 2 liters). It often produces coagulopathy (10\%), especially if it coexists with fetal death $(50 \%)$. The mode and timing of delivery are determined by maternal and fetal commitment. It is possible to opt for an expectant attitude towards early gestational age, without alterations of coagulation or the existence of other maternal and fetal problems. Even so, the general rule is immediate delivery before a placental detachment. ${ }^{24}$

\section{Uterine rupture}

The existence of a previous cesarean is the main risk factor for uterine rupture $(0.2 \%)$. With previous uterine scar, the uterine rupture may be incomplete and not give pain, with the alteration in the FHR (Fetal Heart Rate) being the only symptom together with anarchic uterine contractions or hypertonia. It can also present as a shock in the mother together with severe, continuous and intense abdominal pain. The diagnosis is by manual uterine exploration or laparotomy. There are no significant differences in terms of maternal or perinatal morbidity, whether the rupture occurs in the uterus with a scar or without a scar. Although it is a rare situation, it supposes a high maternal morbidity and mortality and requires immediate surgical treatment. ${ }^{24}$

\section{Vaginal or Cervical Tear}

It occurs in approximately $10 \%$ of the cases, usually associated with an instrumented delivery, the presence of a macrosomic fetus, a delivery that occurs rapidly, before complete cervical dilatation, or the performance of an episiotomy. The diagnosis is made when the existence of uterine atony has been ruled out and the retained placental remains are present. Diagnosis is often late. ${ }^{24,25}$

\section{Placenta Accreta}

It is usually diagnosed after the opening of the uterus because ultrasound and Magnetic Resonance (MR) have low sensitivity. The incidence of placenta accreta is increasing due to the greater number of Cesarean sections performed. Chattopadhyay and his colleagues point out that when the uterus does not present a scar, the incidence of Placental Accretion (PA) is 5\% if there is placenta Previa; with a previous Cesarean scar, the incidence increases to $10 \%$ and with more than one previous Caesarean section, more than $50 \%$ of the patient's present placenta accreta. ${ }^{25,26}$

\section{Uterine Atony}

It is one of the main causes of maternal death after childbirth, especially in developing countries, calculating its frequency in 1:20 births, this is approximately $5 \%$ of all deliveries. A significant proportion of these patients respond to medical treatment, the rest should undergo emergency surgical treatment and others may still occasionally die. ${ }^{25,26}$
Below, there is the description of the main causes of Obstetric Hemorrhage (see Table 2). ${ }^{27,28}$

\begin{tabular}{|c|c|}
\hline ETIOLOGY & DEFINITION \\
\hline $\begin{array}{l}\text { Premature detachment of } \\
\text { placenta normoinserta }\end{array}$ & $\begin{array}{l}\text { It is the partial or total } \\
\text { separation of the placenta } \\
\text { normally inserted after } 20 \\
\text { weeks and before delivery. }\end{array}$ \\
\hline Uterine rupture & $\begin{array}{l}\text { Absence of uterine } \\
\text { contraction. }\end{array}$ \\
\hline Vaginal or cervical tear & $\begin{array}{l}\text { It is the solution of } \\
\text { continuity of the vaginal } \\
\text { and / or cervical mucosa }\end{array}$ \\
\hline Uterine atony & $\begin{array}{l}\text { Early puerperal hemorrhage } \\
\text { due to lack of uterine } \\
\text { contraction. }\end{array}$ \\
\hline Placenta accreta & $\begin{array}{l}\text { Abnormal insertion of part or } \\
\text { all of the placenta without } \\
\text { cleavage plane with } \\
\text { penetration of the chorionic } \\
\text { villi to the uterine wall. }\end{array}$ \\
\hline
\end{tabular}

\section{TREATMENT}

The early recognition of obstetric hemorrhage is considered a diagnostic challenge, since the blood loss remains hidden and difficult to quantify, as a result of the dilution of amniotic fluid and the physiological changes of pregnancy that mask the clinical signs of hypovolemia. ${ }^{23}$

\section{BLEEDING CONTROL. NON-INVASIVE TREATMENT.}

\section{-Drug Treatment (First Line)-}

Oxytocics: in all low-risk postpartum patients, the administration of immediate oxytocics at the outlet of the anterior shoulder preferably followed by controlled traction of the umbilical cord to finally perform late clamping of the umbilical cord in term infants. ${ }^{17}$ The dose to be administered is $10 \mathrm{u}$ of oxytocin, slow intravenous, is one of the preventive recommendations, to keep with $20 \mathrm{u}$ in $500 \mathrm{~mL}$ of glucose solution. $^{29}$

The drug of choice for the treatment of postpartum hemorrhage secondary to atony is oxytocin. ${ }^{17}$ The afterbirth bolus or infusion are good options. They mention that if the first-line uterotonic is not effective in 30 minutes, a second-line medication should be sought. It is important to clarify that bleeding of obstetric origin is a dynamic process, sometimes it is not prudent to wait 30 minutes for proper management in this type of scenarios, so constant evaluation is the key in this type of patients. ${ }^{20}$ 
In post-cesarean patients the drug of choice in post-atony hemorrhages is also oxytocin, the clinical practice guideline recommends administering it in the "rule of 3 ". Six minutes of waiting to start a second-line drug either: ergometrine, Misoprostol or Carbetocin. ${ }^{17,21}$

Ergometrine maleate: $0.2 \mathrm{mg} \mathrm{IM}$ and reevaluate at 10 minutes. $^{28}$

Carbetocin: $100 \mu \mathrm{g}$, IV after release of receptors with $200 \mathrm{~mL}$ of physiological solution to continuous infusion for 5 to 6 minutes. ${ }^{27,28}$

Misoprostol: 800 to $1000 \mu \mathrm{g}$, rectally. (recommendation-c). ${ }^{28}$

Trenexamic acid: it has been suggested in the case of refractory atony or persistent bleeding secondary to genital trauma.

When trenexamic acid is used (dose of $1 \mathrm{~g}$ IV), studies indicate that it is a good medicine that together with oxytocin have proven useful as prevention and treatment. ${ }^{28}$

Another important point is thromboprophylaxis. Whether it is mechanical (compression stockings or intermittent compression) or pharmacological (heparin) for 7-14 days post-partum depending on the risk, there is a scale called Caprini modified that helps select candidates for thromboprophylaxis. ${ }^{23}$

In relation to the pharmacological treatment, there is no specific point about the use of carbetocin first line. Some guides, especially from Canada and London, mention carbetocin even as a first line prophylactic and even treatment in post-cesarean patients or patients with risk factors, this is also a very debatable point. ${ }^{14,17}$

When the uterotonics fail in the vaginal postpartum, a mechanical sequence must be carried out either by bimanual compression (only as a temporary measure in which appropriate care is available for the case), Bakri balloon, uterine impingement vaginally. It is recommended that each hospital develop a hemorrhage care protocol according to the resources needed for adequate care and with constant drills. ${ }^{24}$

\section{Interventionist Treatment (Second Line)}

Bimanual uterine massage, is recommended as a temporary measure until appropriate care is available for the treatment of Pospartum Hemorrhage (PPH) ${ }^{30}$ where one hand is placed in the vagina and pushed against the uterine walls, while the other hand compresses the uterine fundus above the abdominal wall. Uterine tamponade (effective in $84 \%$ of the cases) ${ }^{20}$, the most used device was the Sengstaken-Blakemore Catheter, Barki. $^{24}$
It is important to mention that uterine massage is not indicated in the prevention of postpartum obstetric hemorrhage..$^{20}$ It is indicated only as a temporary measure. Continuous uterine massage is not recommended as an intervention to prevent a hemorrhagic event in women who have received prophylactic oxytocin, since it can cause maternal discomfort. ${ }^{21}$

Impingement of the umbilical cord should be delayed in neonates that allow it (1-3 min). In caesarean sections, controlled traction of the umbilical cord is indicated as a measure of choice over manual delivery. ${ }^{22}$

Placement of a balloon (Cobra cordis 5F) to the internal iliac artery through the common femoral artery, following the Seldinger technique, at a pressure of 1-2 atm., it is insufflated and left for 24 hours to 48 hours, with prophylaxis antibiotic, this procedure is safe, effective and can be performed on unstable patients. It is important to have the support of an experienced radiologist. ${ }^{24}$

Anti-shock clothing, there are no randomized studies that recommend it, the possibility of benefiting the patient is to decrease blood loss $200 \mathrm{~mL}$. External aortic compression is also a recommended measure. Emphasize that these measures are appropriate in the first level of care and for the safe transfer of a patient, as well as scenarios in which secondary haemorrhages may occur with accreta, placenta in previous pregnancies, etc. ${ }^{20}$

\section{BLEEDING CONTROL. SURGICAL TREATMENT}

\section{-Conservative Surgery-}

Ligation of uterine artery immediately after delivery, the success is $90 \%$, even more if one has placental accreta data due to its high risk of maternal morbidity and mortality.

The clamping of uterine arteries via the vagina should be part of the protocol of containment of the hemorrhage. However, we must not forget that they are temporary measures in which appropriate care is available according to the basic cause. ${ }^{24}$

Ligation of the internal iliac artery effective $84 \%$. Women subjected to any of the aforementioned ligatures are likely to maintain their reproductive capacity.

It is important to mention that for cases in which intrauterine packing is required, it is not advisable to perform it by using compresses or gauze. In these cases, it is preferable to use uterine hydrostatic tampons, the first line is the bakri balloon mentioned above, which must be managed if the hospital has the resource, otherwise there are other measures such as the use of a Foley catheter. $^{26}$

Fogarty catheter balloon, placed in the internal iliac artery during the preoperative period without complications in the caesarean section hysterectomy. ${ }^{23}$

In the postpartum period, intrauterine tamponade with bakri balloon should be the first line of treatment in the face of postpartum hemorrhage refractory to medical treatment, 
bimanual compression and clamping of the uterine arteries via the vagina are temporary measures that help to have everything ready for proper attention. The Clinical Practice Guideline mentions that the tampon must remain at least 6 hours. The ideal would be to keep it for 12-24 hours, the recommendation is to deflate it gradually and with surveillance. ${ }^{25,26}$

Uterine compression sutures (B-lynch) ${ }^{26}$ are effective in $91 \%$ of the cases. However, there is a risk of uterine necrosis, intrauterine and abdominal adhesions, as well as pyometra. ${ }^{28}$

Multiple square sutures safe procedure for massive postpartum hemorrhage, associated with few complications of infection, ischemia and adhesions. ${ }^{24}$ According to Doumouchtsis there are no statistically significant differences between the various procedures such as bimanual compression, uterine plug, embolization and / or ligation of uterine artery, ligation of iliac arteries and uterine compression sutures. ${ }^{31}$

Special recommendations: In post-cesarean and atony patients and in those with whom drugs did not work, it is suggested to start with compressive sutures such as B-lynch. Another suitable suture is Hayman which is useful in patients without hysterotomy. ${ }^{26}$ As a second line and to some extent its use is controversial because it is recommended that it be first line, sutures can be used and first line sequential uterine desarterialization: ligation of uterine arteries-compressive sutures, sequential arterial ligatures and finally hypogastric arteries, although its routine or prophylactic ligation is not indicated..$^{25,26}$

The truth is that medical units of medium and high resolution must have trained personnel and permanently trained in conservative surgical techniques for the management of bleeding. ${ }^{19}$ Hysterectomy (HTA) should never be delayed in patient's refractory to these treatments or in cases of placenta accreta or uterine ruptures. It must be done by the most experienced personnel in these cases. ${ }^{19-21}$

\section{RADICAL SURGERY}

Neuraxial (regional) anesthesia is the technique of choice. General anesthesia is preferred in hemodynamically unstable patients with coagulopathy. ${ }^{18,24}$

Hysterectomy continues to be the option of bleeding control to save the life of the patient. It is done to save life and before triggering a coagulopathy. ${ }^{19}$

The incidence of cesarean section hysterectomy has increased not by postpartum haemorrhage but basically by placental presentation abnormalities (placental accreta). ${ }^{20}$

\section{CONSIDERATIONS FOR TRANSFUSION}

The therapeutic goals of managing massive blood loss is to keep hemoglobin $(\mathrm{Hgb})$ greater than $8 \mathrm{~g} / \mathrm{dL}$ platelet count greater than
50,000. TP less than 1.5 times normal. TTP less than 1.5 times normal. Fibrinogen greater than $200 \mathrm{mg} / \mathrm{dL}^{23}$

The volume replacement should be with isotonic crystalloid solutions. They should not use synthetic colloids. The best of the replacement is a goal-directed therapy to maintain tissue perfusion guided by hemodynamic flow monitoring and timely therapeutic intervention. ${ }^{20}$

During active bleeding it is advisable to maintain hemoglobin concentrations of 7 to $9 \mathrm{~g} / \mathrm{dl}$. However, we believe that these patients should not be monitored with hg since it is a parameter that may not reflect the actual clinical context of the patient, but not with coagulation tests including fibrinogen, platelets, and serum lactate. ${ }^{23}$

Transfusion algorithms that incorporate monitoring with viscoelastic coagulation tests are effective in reducing bleeding losses and reducing exposure to allogeneic blood and improving safety. ${ }^{23}$

If it is decided to use a transfusion protocol, it must be related to a fixed product, which replaces coagulation factors and an individualized precoagulant intervention. ${ }^{23,28}$

Politransfusion is recommended when the INR is $>1.5$ (fresh frozen plasma), platelets $<25000$ (platelet concentrates) and fibrinogen $<100 \mathrm{mdl}$ (cryoprecipitate).

All hemorrhages greater than $1500 \mathrm{~mL}$ should be evaluated in a clinical review. ${ }^{23}$

\section{GUIDELINES FOR THE MANAGEMENT OF OBSTETRIC HEMORRHAGE}

In order to approach this entity, there are currently clinical practice guidelines that aim at making the recommendations based on the best available evidence available to health care staff with the objective of:

-Improve the quality of care of the obstetric patient with risk or presence of hemorrhage. ${ }^{16}$

-Promote the use of clinical practices that are based on the best available scientific knowledge and that can be applied in the hospital units with obstetric care. ${ }^{17}$

-To serve as a support tool for the surveillance and management of patients with risk or presence of obstetric hemorrhage, without replacing the medical criteria and according to the specific characteristics of each patient. ${ }^{22}$

In the following paragraphs there are the recommended guidelines to manage an obstetric hemorrhage:

\section{World Health Organization (WHO) Guide}

The prevention, treatment and organization recommendations are the following: 
-Use of uterotonic agents (oxytocin) for the prevention of obstetric hemorrhage.

-Late cord clamping (performed approximately 1 to 3 minutes after birth) for all deliveries, at the same time that the simultaneous essential care of the newborn is started.

-The controlled cord traction is the recommended method for the removal of the placenta in caesarean section.

-The use of isotonic crystalloids is recommended in preference to the use of colloids for the intravenous fluid resuscitation of women with PPH.

-Use of tranexamic acid is recommended for the treatment of PPH if oxytocin and other uterotonics fail to stop the bleeding or if it is thought that the bleeding may be partly due to trauma.

-The use of formal protocols by health facilities for the prevention and treatment of PPH is recommended, as well as the use of formal protocols for referral of women to a higher level of care is recommended for health facilities. ${ }^{6}$

Once the obstetric hemorrhage is diagnosed it is important to have an alert system that activates a code for the multidisciplinary team, this type of code is the so-called "MATER CODE"28. It must be effective in all hospitals. The cause of primary hemorrhage should always be sought (uterine atony is responsible for $70 \%$ of the cases of primary postpartum hemorrhage). ${ }^{25}$

Anesthesiologists play an important role in the multidisciplinary team. Ideally, all pregnant patients should have a pre-anesthetic assessment. The first level units and some second level units do not have this service. ${ }^{18}$

\section{National Institute for Health and Care Excellence (NICE) Guide}

Obstetric hemorrhage is no longer a major cause of maternal death in the United Kingdom. In the 2006-2008 report of the UK confidential investigation on maternal deaths, bleeding was the sixth highest direct cause. The nice guidelines have the following focus: identification of risk factors (prenatal risk factors, factors related to pregnancy), presentation (signs and symptoms), associated diseases and management. ${ }^{5,7}$

The guidelines of the royal college of obstetricians and gynecologists (RCOG) recommend four components of management to be instigated at the same time, once postpartum haemorrhage (PPH) has been identified. These are: ${ }^{14,24}$

-Communication alerts to all health professionals involved in the management of the hemorraghe (obstetricians, anesthesiologists, intensivists, blood bank). ${ }^{21}$

-Revival. Early infusion of crystalloid solutions, evaluate airway, circulation, oxygen by mask at 10-15 liters per minute. Transfuse blood as soon as possible, if clinically required.

Infusions should be heated and a blood filter should not be used. $^{23}$
-Follow-up and research, global and viscoelastic coagulation tests, and continuous monitoring with surveillance of renal function. Records of all parameters in the flow chart, for example, the Modified Early Obstetric Warning System (MEOWS). ${ }^{16}$

-Measures to stop bleeding. Physical examination to establish the etiology of obstetric hemorrhage. Use uterotonics as a firstline drug if it is considered uterine atony. ${ }^{7}$

\section{CONCLUSIONS}

Maternal mortality (MM) is one of the main concerns of public health and represents a good indicator to measure the quality of care, therefore, even if it is important to incorporate prevention practices, obstetric hemorrhage is an urgent need that requires an adequate and timely action of a duly trained multidisciplinary team to control the event either by mechanical or pharmacological measures, or both. To this end, action guidelines, protocols to study the risk factors and informed consents have been prepared, all based on evidence-based medicine and considering the opinions of experts.

That is why it is suggested that Obstetric Triage and code activation systems such as the Mater Code are implemented in all health institutions. This would represent a great advance in the improvement of response protocols to face an obstetric event of this magnitude.

\section{REFERENCES}

1. Plan Estatal de Desarrollo Hidalgo 2016-2022 Visión prospectiva 2030. Gobierno del Estado de Hidalgo. [Document on the internet] Pachuca de Soto 2017. [Cited March 2019] Available on: http://planestataldedesarrollo.hidalgo.gob.mx/pdf/PED/PED/Ped_Com pleto.pdf

2. Rojas AJ, Cogollo M, Jezid EM, Ramos CE, Fernández CJ, Bello MA. Morbilidad materna extrema en cuidados intensivos obstétricos Cartagena Colombia: 2006-2008. Rev. Colomb. Obstet. Ginecol. 2011; 62(2):131-140.

3. Secretaría de Salud. Búsqueda intencionada de muertes maternas y de menores de cinco años, y Registro de nacimientos en los 101 municipios con bajo índice de desarrollo humano. [Document on the internet]. México 2013. [Cited March 2019] Available on: www.dgis.salud.gob.mx/descargas/pdf/BIMMyM5.pdf

4. González Ortíz LD, Gómez Arias RD, Vélez Álvarez GA, Agudelo Londoño SM, Gómez J, Wylie J. Características de la atención hospitalaria y su relación con la morbilidad materna extrema en Medellín, Colombia. Rev. Panam. Salud Publica. 2014; 35(1):15-22.

5. United Nations. Objetivos de Desarrollo Sostenible. 2017. [Document on the internet] 2017. [Cited March 2019]. Available on: http://www.un.org/sustainabledevelopment/es/objeetivos-dedesarrollo-sostenible/

6. Mavrides E, Chandraharan E, Collins P, Green L, Hunt BJ, Riris S, et al. Prevention and Management of Postpartum Haemorrhage: Green-top Guideline. BJOG. 2017; 52:106-49.

7. World Health Organization. Evaluating the quality of care for severe pregnancy complications. The WHO near-miss approach for maternal health. [Document on the internet]. 2013. [Cited march 19]. Available on:

https://www.who.int/reproductivehealth/publications/monitoring/9789 241502221/en/ 
8. Camacho-Castro FA, Rubio Romero JA. Recomendaciones internacionales para el tratamieto medico de la hemorragia posparto. Rev. Fac. Med. 2016; 64 (1): 87-92.

9. World Health Organization. Mortalidad Materna, datos y cifras. [Document on the internet] 2016. [Cited March 2019]. Available on: http://apps.who.int/mediacentre/factsheets/fs348/es/index.html

10. Alkema L, Chou D, Hogan D, Zhang S, Moller B, Gemmill A, et al Global, regional, and national levels and trends in maternal mortality between 1990 and 2015, with scenario-based projections to 2030: a systematic analysis by the UN Maternal Mortality Estimation InterAgency Group. Lancet. 2016;387(10017):462-74.

11. Hospital Donostia. Protocol: Manejo multidisciplinario de la hemorragia obstétrica masiva. Hospital Donostia. [Document on the internet]. 2014 [Cited March 2019]. Available on: http:// www.osakidetza.euskadi.net/r85ckcmpn05/es/contenidos/informacion/ hd_publicaciones/eshdon/adjuntos/Protocolo45HemorragiaObstetrica.p df

12. Apichart Chittacharoen. Surgical Management of Massive Postpartum Hemorrhage with Uterin Atony. JGWH. 2017;(5): 01-03.

13. Observatory of Maternal Mortality in Mexico. Maternal Mortality Bulletin 2018; [Document on the internet] 2018. [Cited March 2019]. Available on: http://www.omm.org.mx/index.php/indicadoresnacionales/boletines-de-mortalidad-materna/2018

14. American College of Obstetricians and Gynecologists. ACOG Practice Bulletin: Clinical management guidelines for obstetriciangynecologists: Postpartum hemorrhage. 2017;130(4):168-86.

15. Werner H.R WH. Postpartum hemorrhage. Update on problems of definitions and diagnosis. AOGS. 2011; 90:421-8.

16. World Health Organization. WHO guidelines for the management of postpartum haemorrhage and retained placenta. WHO; [Document on internet]. 2009. [Cited March 2019]. p. 1-62. Available on: http://whqlibdoc.who.int/publications/2009/9789241598514

17. Royal College of Obstetricians and Gynaecologists. RCOG release: FIGO President discusses management of postpartum haemorrhage at Qatar conference. [Document on internet]. 2014 [Cited March 19]. Available on: https://www.rcog.org.uk/en/news/rcog-release-figopresident-discusses-management-of-postpartum-haemorrhage-at-qatarconference/

18. Llau JV, Acosta FJ, Escolar G, Fernández-Mondéjar E, Guasch E, Marco $\mathrm{P}$, et al. Multidisciplinary consensus document on the management of massive haemorrhage. Med Intensiva. 2015 nov; 39(8):483-504

19. Guasch E, Gilsanz F. Treatment of postpartum hemorrhage withblood products in a tertiary hospital: Outcomes and predictive factor associated with severe hemorrhage. Clin. Appl. Thromb. Hemost. 2015 22 (7):685-692

20. Dirección General de Salud Reproductiva., Secretaria-de-Salud. Manua de atención: Urgencias obstétricas en unidades de primer nivel. In. D.F. México: D.F: Secretaria de Salud; 2001

21. Secretaría de Salud, CENETEC. Prevención y manejo de la Hemorragia posparto en el primero, Segundo y tercer nivel de atención. Resumen de Evidencias y Recomendaciones: Guía de Práctica Clínica de enfermería. México. 2017; 07-24

22. Secretaría de Salud. Instituto Mexicano del Seguro Social (IMSS) Diagnóstico y tratamiento de la hemorragia obstétrica en la segunda mitad del embarazo y puerperio inmediato. Guía de Práctica Clínica. México. 2009; 162-09.

23. Abdul-Kadir R, McLintock C, Ducloy AS, El-Refaey H, England A Federici AB. Evaluation and management of postpartum haemorrhage: consensus from an international expert panel. Transfusion medicine reviews. 2014; 54 (7): 1756-1768.
24. Mercier J, Van de Velde M. Major Obstetric Hemorrhage. Journal of Anesthesiology Clinics. 2008; 26(1): 53-66.

25. Pérez Solaz A, Ferrandis Comes R, LLau Pitarch JV, Alcantara Noalles MJ, Abengochea Cotaina A, Barberá Alacreu M, et al. La hemorragia obstétrica. Actualizacion. Rev. Esp. Anestesiol. Reanim. 2010; 57(4):32-43.

26. Chattopadhyay SK, Kharif H, Sherbeeni MM. Previous Placenta and accreta after previous caesarean section. Eur. J. Obstet. Gynecol. Reprod. Biol. 1993; 52(3):151-6.

27. Solari AA, Solari GC, Wash FA, Guerrero GM, Enríquez GO. Hemorragia postparto. Principales etiologías, su prevención, diagnóstico y tratamiento. Rev. Med. Clin. CONDES. 2014; 25(6):9931003

28. Plaat F, Shonfeld A. Major Obstetric Haemorrhage. BJA. 2015; 15(4):190-193

29. Guasch E, Gilsanz F. Hemorragia masiva obstétrica: enfoque terapéutico actual. Med. Intensiva. 2016;40(5):298-310.

30. Word Health Organization. Recomendation on the use of bimanual uterine compression for the treatment of pstpartum haemorrhage. [Document on the internet]. 2012. WHO. Available on: http: //extranet.who.int/rhl/topics/preconception-pregnancy-childbirth-andpostpartum-care/care-during-childbirth/care-during-labour-3rdstage/who-recommendation-use-bimanual-uterine-compressiontreatment-postpartum-haemorrhage.

31. Doumouchtsis SK, Papageorghiou AT, Vernier C, Arulkumaran S. Management of postpartum hemorrhage by uterine balloon tamponade: prospective evaluation of effectiveness. Acta Obstet Gynecol Scand. 2008; 87:849-55. 